\title{
CAIM: UMA PARÓDIA DO VELHO TESTAMENTO
}

Caroline de Almeida Nascimento ${ }^{1}$

RESUMO: Este artigo tece considerações acerca do narrador, do grotesco e da carnavalização no romance Caim (2009) escrito por José Saramago, a partir dos conceitos bahktinianos de dialogismo e modalidades discursivas. Objetiva-se assim, compreender a ressignificação que o autor português propõe ao reler, através do emprego de recursos irônicos e críticos, as histórias bíblicas amplamente conhecidas na tradição judaico-cristã.

PALAVRAS-CHAVES: Saramago, Caim, Dialogismo, Bakhtin.

\section{CAIM: A PARODY OF THE OLD TESTAMENT}

\begin{abstract}
This article presents considerations regarding the narrator, the grotesque and the carnivalization in the novel Caim (2009) written by José Saramago, taking into consideration the concepts of dialogism and discursive modalities of Bahktin. This article aims at understanding the new meaning that the Portuguese author proposes by re-reading widely known Bible stories from the Jewish-Christian tradition, through the use of resources such as irony and criticism.
\end{abstract}

KEYWORDS: Saramago, Caim, Dialogism, Bakhtin.

\footnotetext{
${ }^{1}$ Mestranda na área de Literatura Portuguesa (Universidade de São Paulo), desenvolve projeto de estudos sobre o teatro do autor português contemporâneo Helder Costa.
} 


\section{Introdução}

A obra do autor português José Saramago é reconhecidamente polêmica. O adjetivo, comumente associado a ela, encontra escopo na predileção autoral pelo trato de assuntos delicados, por vezes dogmáticos aos olhos do público. Em conformidade com esta característica está o livro Caim, derradeira obra do autor, publicado ainda em vida, no ano de 2009.

Vista por muitos como outra "alfinetada" aos princípios católico-judaicos da sociedade contemporânea, a obra trata do tema religioso de forma ainda mais intensa do que $O$ Evangelho segundo Jesus Cristo, abordando passagens bíblicas amplamente conhecidas e atribuindo-lhes uma nova interpretação a partir da personagem central que intitula o romance: Caim. Assim, o objetivo deste artigo é abordar com maior profundidade o narrador e o grotesco como elementos estruturais e a carnavalização como elemento interpretativo na referida obra, cuja temática é a história dos homens, vista como: “[...]a história dos seus desentendimentos com deus, nem ele nos entende a nós, nem nós o entendemos a ele" (SARAMAGO, 2009, p. 9).

Antes de qualquer análise sobre os aspectos internos da obra, comentemos sobre seu título, clara alusão à figura bíblica de Caim, assassino de seu irmão Abel e descendente direto de Adão e Eva. Comumente associado ao lado perverso do ser humano, Caim, cuja existência na tradição judaico-cristã serve de antiexemplo, encontra no livro de Saramago lugar de destaque.

Do ponto de vista etimológico, o substantivo Caim, de origem hebraica, associa-se a dois significados distintos: a transliteração de Qayin, derivado da forma verbal Qanah, que significa obter ou provocar ciúmes; ou ainda relacionado à expressão "algo produzido".

\section{O narrador - Estilos, tipos e formas do discurso}

O acadêmico Erich Auerbach, no primeiro capítulo de seu livro Mimesis: a representação da realidade na literatura ocidental, confronta, a partir de excertos, dois estilos narrativos: o homérico e o bíblico. Segundo ele:

De um lado, fenômenos acabados, uniformemente iluminados, definidos temporal e espacialmente, ligados entre si, sem interstícios, num primeiro plano; pensamentos e sentimentos expressos; acontecimentos que se desenvolvem com muito vagar e pouca tensão. Do outro lado, só é 
acabado formalmente aquilo que nas manifestações interessa à meta da ação; o restante fica na escuridão. Os pontos culminantes e decisivos para a ação são os únicos a serem salientados; o que há entre eles é inconsistente; tempo e espaço são indefinidos e precisam de interpretação (...) (AUERBACH, 2009, p.9).

Ao estilo homérico, atribuiu características como a digressão, o detalhamento e a presentificação dos acontecimentos; enquanto que, ao estilo bíblico, associou o predomínio do conhecimento imediatamente necessário aos limites da ação descrita, bem como a ausência de indicativos de temporalidade.

Embora Caim esteja ligado à temática da religião, o romance caracteriza-se por uma acentuada mescla de estilos narrativos. Do estilo homérico, tem-se a continuidade (independente de digressões ou mudanças de planos, a narrativa não cessa). Esta é sempre feita no plano presente, como se o que fosse narrado estivesse ocorrendo ao mesmo tempo em que é contado. Do estilo bíblico, ressalta-se a presença do espaço interpretativo, utilizado pela personagem Caim para manifestar opiniões e questionamentos sobre o que é narrado. O leitor é convidado a partilhar das intervenções e opiniões da personagem. Aliada a esta característica, encontra-se a intencionalidade da narrativa, ou seja, a predileção em narrar fatos e aspectos que justifiquem os comentários do narrador.

Além do estilo do discurso, cabe também analisar suas modalidades. O teórico russo Mikhail Bakhtin teceu uma relação entre os diferentes modelos de discurso e o papel do herói e do narrador como manifestação desta escolha. Assim, diagnosticou a existência de três tipos diferentes de manifestação discursiva.

Segundo o linguista russo, o primeiro tipo de discurso seria o referencial direto e imediato, que visaria à interpretação referencial direta do objeto tratado. Este discurso conhece apenas a si mesmo, podendo ser representado por outro discurso dentro do romance, tal como o narrador. "O autor inclui no seu plano o discurso do outro voltado para as próprias intenções.” (BAKHTIN, 2010. p.221). No segundo modelo, o discurso do herói seria representado e objetificado e, por este motivo, não se situaria no mesmo plano do discurso do autor. Na maioria das vezes, subordina-se a ele, como uma espécie de objeto da intenção do autor.

Já no terceiro modelo discursivo, o autor ou se faz passar pelo discurso de outro ou faz este passar por seu discurso (através do princípio dialógico). Quando se trata de polêmica velada ou não, a opção por este discurso, conhecido como variedade ativa devido à interferência direta no discurso do autor, permite a ele maior mobilidade. 
Em Caim, vemos a opção pelo terceiro modelo de discurso, uma vez que as vozes do romance, ainda que opostas, mesclam-se na construção dialógica da obra. Os episódios narrados são construídos como uma colcha de retalhos, em que cada voz contribui para a constituição do todo. O caráter dialógico (com momentos polifônicos) dos romances de Saramago quase que, por definição, o encaixam no último grupo.

Em seu trabalho sobre a poética de Dostoievski, especialmente focado na ocorrência do fenômeno da polifonia, Mikhail Bakhtin afirma que: "Em linhas gerais, a narração se desenvolve entre dois limites: entre o discurso secamente informativo, protocolar, de modo algum representativo, e o discurso do herói." (BAKHTIN, 2012, p. 290). Para ele, a narração é o resultado de dois referenciais: a voz do autor/narrador (descrição dos fatos) e a voz do herói como uma espécie de "agente" do que é descrito. No romance de Saramago, o narrador e a personagem de Caim estão fortemente ligados, dando a impressão de que se revezam nas opiniões acerca do que é narrado.

No tocante às formas do discurso, recordaremos alguns conceitos, por meio de exemplos retirados de Caim. O discurso direto consiste em dar espaço para a fala da própria personagem (indicado pelas palavras em destaque):

(...) Lançaram-na ao mar tal como se encontrava, ensanguentada, suja de excrementos, um mísero despojo humano sem honra nem dignidade. Por que não a limparam antes, perguntou caim, e noé respondeu, Vai ter muita água para se lavar. (SARAMAGO, 2009. p.165).

O emprego do discurso direto evidencia o caráter dialógico da obra, uma vez que pressupõe a existência de várias vozes, que dialogam entre si. Cabe ressaltar que o romance Caim, assim como grande parte da obra de Saramago, não é polifônico por completo, como as obras de Dostoiévski são para Bakhtin, porém contém momentos de polifonia (presença de várias vozes que não se subordinam à voz autoral na busca por suas identidades). Em certa medida, ainda que não seja totalmente polifônico, Caim enquadra-se no rol das obras saramaguianas que têm por mote a busca pela verdade e pela autoconsciência.

Também no emprego do discurso indireto, que ocorre quando o narrador reproduz o que as personagens disseram (em destaque), evidencia-se o papel dominante que este exerce sobre as demais vozes do romance:

Espera-se a todo o momento o assalto do exército de Josué e, por mais que Caim tivesse jurado que não era israelita, negaram-lhe o acesso, sobretudo porque não teve nenhuma resposta satisfatória para dar quando lhe perguntaram, Que és então se não és israelita. (SARAMAGO, 2009, p.109). 
O domínio da voz do narrador no romance não impede que o controle sobre as demais vozes seja "relaxado" e que estas se tornem, ainda que momentaneamente, independentes. A personagem Caim configura-se como uma voz que, ora se vê subordinada ao narrador, ora está livre para manifestar-se, ainda que, muitas vezes, apenas para corroborar o ponto de vista do narrador.

Finalmente, o discurso indireto livre que se dá a partir do enfraquecimento da voz do narrador, vagarosamente cedendo lugar à voz das personagens, embora não haja a concessão da palavra de modo explícito a elas (em destaque, as falas que seriam da personagem, porém aparecem sem prévia indicação):

Caim mal podia acreditar no que os seus olhos viam. Não bastavam sodoma e gomorra arrasadas pelo fogo, aqui, no sopé do monte sinai, ficara patente a prova irrefutável da profunda maldade do senhor, três mil homens mortos só porque ele tinha ficado irritado com a invenção de um suposto rival em figura de bezerro, Eu não fiz mais que matar um irmão e o senhor castigou-me, quero ver agora quem vai castigar o senhor por estas mortes, pensou caim, e logo continuou, Lúcifer sabia bem o que fazia quando se rebelou contra deus, há quem diga que o fez por inveja e não é certo, o que ele conhecia era a maligna natureza do sujeito. (SARAMAGO, 2009, p.101).

O uso do discurso indireto livre em Caim evidencia a figura do narrador como centro irradiador e onisciente dos fatos descritos, uma vez que as intervenções das personagens (pensamentos, falas e ações), especialmente de Caim, configuram-se como extensão da voz do narrador. Como bem define o teórico Oscar Tacca, em seu livro As vozes do romance, de 1978: "A visão do narrador determina, pois, a perspectiva do romance.” (p.67), sendo, ao mesmo tempo, o representante da vOz autoral dominante e o espaço dos momentos polifônicos da obra. Em Caim, o narrador exerce o papel de guia que circula com o leitor por um velho testamento nunca antes visto por esta perspectiva.

Passemos agora ao elemento temporal e espacial da obra. Como sugere Tacca:

Não obstante, quando se trata de delimitar o problema do narrador - ou de distinguir, em relação a este, as diferentes formas de relato - observase que tal categoria é insuficiente. Com efeito, de um ponto de vista estritamente narrativo, as variações estão em relação com diferentes instâncias: autor, narrativa, narrador, personagens, tempo, destinatário. (TACCA, 1978, p. 26)

Embora Caim não estabeleça compromisso com a ordem espacial e temporal da narrativa bíblica, devido à sua não-linearidade (justificada por um mecanismo complexo que o narrador se exime de comentar), vale mencionar que é nesta aparente desorganização que repousa o processo de autoconsciência de Caim. 
A personagem busca, ao longo de toda a narrativa, sua identidade e lugar no mundo após cometer o assassinato de seu irmão. Contudo, presencia, durante os eventos em que toma parte, a manifestação do aspecto demoníaco de Deus, passando de observador passivo a contestador da figura divina. As mudanças de espaço e tempo no romance acentuam o processo pelo qual Caim e nós, como leitores, passamos ao longo da narrativa. A associação entre esta aparente desordem e a presença de um narrador irônico lança um novo olhar sobre o que é tido como incontestável na religião: a figura de Deus.

\section{O Aspecto Grotesco}

Além do narrador, outro elemento estrutural que merece destaque é o grotesco. Bakhtin, em seu livro A cultura popular na Idade Média e no Renascimento: o contexto de François Rabelais, dedica-se ao tema. Segundo ele, o mais significativo dos trabalhos foi o de Schneegans, cuja visão sobre o efeito do recurso contemplava, fundamentalmente, a esfera do caricatural, evidenciando os aspectos negativos e extremos do que era representado. Segundo Bakhtin: "Schneegans não pôde encontrar o bom caminho que dá acesso ao grotesco, nem compreender que seja possível unir numa única imagem os polos positivo e negativo". (BAKHTIN, 1999, p.269).

Para ele, o grotesco pode ser definido como uma "transmutação de certas formas em outras, no eterno inacabamento da existência" (BAKHTIN apud DISCINI, 2010, p. 58). O espetáculo da representação do grotesco consiste em: “(...) assistir-se ao rebaixamento dos objetos de uma outra ordem, seguido de sua renovação no plano do 'baixo"'. (BAKHTIN, 1999, p.271).

O linguista russo sugere que o grotesco seja compreendido como um instrumento de ressignificação dos elementos aos quais é aplicado, e não apenas como chiste ou rebaixamento. Para ele, o ponto central não deve estar na comicidade, mas no motivo pelo qual ela é criada. Em posse destas reflexões, analisemos dois fragmentos que narram o mesmo evento: a criação do homem por Deus - um retirado da Bíblia e outro do romance de Saramago.

(.... ${ }^{26}$ Então Deus disse: 'Façamos o homem à nossa imagem e semelhança. Que ele reine sobre os peixes do mar, sobre as aves dos céus, sobre os animais domésticos e sobre toda a terra, e sobre todos os répteis que se arrastem sobre a terra $(. . .)^{7} \mathrm{O}$ Senhor Deus formou, pois, o homem do barro da terra, e inspirou-lhe nas narinas um sopro de vida e o homem se tornou um ser vivente". (Bíblia - Gênese: I - As origens) 


\begin{abstract}
(...) quando os outros animais, produtos, todos eles, tal como os dois humanos, do faça-se divino, uns por meio de mugidos e rugidos, outros por roncos, chilreios, assobios e cacarejos, desfrutavam já de voz própria. Num acesso de ira, surpreendente em quem tudo poderia ter solucionado com outro rápido fiat, correu para o casal e, um após outro, sem contemplações, sem meias-medidas, enfiou-lhes a língua pela garganta abaixo. (SARAMAGO, 2009, p.9)
\end{abstract}

Mesmo ao leitor desatento, não escapa o tom narrativo distinto nos dois fragmentos. A começar pelo primeiro, tem-se o emprego de linguagem neutra, em que predomina o uso de palavras rebuscadas e menos descritivas, especialmente nas falas atribuídas a Deus. Sua figura é associada à perfeição, tanto dele quanto de sua criação, uma vez que esta é feita à sua imagem e semelhança.

Já no segundo fragmento, a linguagem empregada é coloquial, além de irônica, especialmente quanto à "solução" pouco cuidadosa de Deus para resolver a ausência da fala no ser humano. A figura divina é associada a sentimentos como raiva e impulsividade, em consequência da falha cometida na criação. A sugestão de que o homem foi uma "experiência científica" para Deus será reforçada textualmente através das falas do anjo que guarda o paraíso.

Vejamos outros fragmentos em que o grotesco se faz presente:

Dito isto, o senhor fez aparecer umas quantas peles de animais para tapar a nudez de adão e eva, os quais piscaram os olhos um ao outro em sinal de cumplicidade, pois desde o primeiro dia souberam que estavam nus e disso bem se haviam aproveitado. (...) Carregando sobre os ombros as fedorentas peles, bamboleando-se sobre as pernas trôpegas, adão e eva pareciam dois orangotangos que pela primeira vez se tivessem posto de pé. (SARAMAGO, 2009, p. 18).

Eva retirou a pele de cima dos ombros e disse, Usa isto para trazeres a fruta. Estava nua da cintura para cima. A espada silvou com mais força como se tivesse recebido um súbito afluxo de energia, a mesma energia que levou o querubim a dar um passo em frente, a mesma que o fez erguer a mão esquerda e tocar no seio da mulher. Nada mais sucedeu, nada mais podia suceder, os anjos, enquanto o sejam, estão proibidos de qualquer comércio carnal, só os anjos que caíram são livres de juntar-se a quem queiram e a quem os queira. Eva sorriu, pôs a mão sobre a mão do querubim e premiu-a suavemente contra o seio. (SARAMAGO, 2009, p. 25).

No primeiro trecho, o narrador enfatiza o conhecimento de Adão e Eva sobre sua nudez e indica, de modo malicioso, que, em posse desta informação, os dois teriam se aproveitado da situação. A consciência de si e do outro é representada como elemento 
positivo, em oposição ao que ocorre na narração bíblica, em que a aquisição da consciência é uma forma de castigo por terem desobedecido a Deus. Em Caim, no momento em que as personagens cobrem-se e agem como se a consciência fosse algo negativo, são comparados a seres primatas, orangotangos, cuja racionalidade é questionável. No segundo excerto, Eva retira a pele que lhe cobre o busto e entrega-a ao anjo, que sente "curiosidade" pela humana e toca-lhe. A mulher não o rejeita, ao contrário, estimula-o, pressionando as mãos do querubim contra seus seios.

A presença do elemento grotesco insere-se nas ações das personagens e tem efeito na medida em que quebra as expectativas do leitor. O desejo na figura do anjo e a concordância de Eva dão início ao processo pelo qual todas as personagens passam ao longo do romance: o da ressignificação.

No romance, recontam-se histórias bíblicas, imprimindo-lhes um olhar racionalista, pautado pelo questionamento acerca da veracidade e plausibilidade do que nelas é narrado, ainda que sejam incondicionalmente aceitas por muitos que a leem.

Desde o início, o narrador agrega à figura divina características que questionam, ou pelo menos colocam em dúvida, a correspondência entre Deus e os atributos positivos comumente associados a ele. Em sentido oposto, Caim é descrito como o assassino com mais "divindade" de ações e sentimentos do que o próprio Deus. Há, ao longo de todo o romance, o emprego do grotesco como forma de ressignificar tanto a figura de Deus quanto as narrativas bíblicas.

\section{Carnavalização}

O realismo grotesco tem como propriedade fundante arremeter contra o discurso especular. Sua força transgressora é mais intensa quando o discurso que deve se refletir no espelho já exibe aspectos da degeneração a que é submetida a linguagem cada vez que é utilizada para construir enunciados cuja estrutura obedece a formas consagradas pelo uso ou padronizadas segundo os moldes do agrado daqueles que, na dinâmica da cultura, ditam e preservam as normas imperativas do poder dominante e, com base nele, fabricam em série combinatórias sígnicas extremamente surradas (CAÑIZAL, In: BRAIT 2010, p. 250).

O elemento grotesco, pertencente ao nível estrutural do romance, encontra seu correspondente interpretativo no recurso da carnavalização. De acordo com a etimologia alemã para o termo, Karne ou Karth significa "lugar santo" e $V$ al (ou wal) associa-se a morto ou assassinado. Segundo Bakhtin, o elemento da carnavalização se dá a partir de quatro procedimentos distintos, sendo eles: o livre contato familiar entre os homens (ausência 
da hierarquia), a excentricidade (fuga dos padrões comuns), as mésalliances carnavalescas (familiarização) e a profanação (subversão do sagrado).

O aspecto subversivo, com especial ênfase na morte do sagrado, encontra espaço frutífero no romance de Saramago. A opção pela grafia em letras minúsculas de palavras como Deus e Senhor indica a intenção de rebaixar estes elementos ao mesmo plano de objetos e coisas.

Observemos os fragmentos abaixo, extraídos de Caim:

O leitor leu bem, o senhor ordenou a abraão que lhe sacrificasse o próprio filho, com a maior simplicidade o fez, como quem pede um copo de água quando tem sede, o que significa que era costume seu, e muito arraigado. O lógico, o natural, o simplesmente humano seria que abraão tivesse mandado o senhor à merda, mas não foi assim. Na manhã seguinte, o desnaturado pai levantou-se cedo para pôr os arreios no burro, preparou a lenha para o fogo do sacrifício e pôs-se a caminho para o lugar que o senhor lhe indicara, levando consigo dois criados e o seu filho isaac.(SARAMAGO, 2009, p. 79, grifos nossos).

Perguntou isaac, Pai, que mal te fiz eu para teres querido matar-me, a mim que sou o teu único filho, Mal não me fizeste, isaac, Então por que quiseste cortar-me a garganta como se eu fosse um borrego, perguntou o moço, se não tivesse aparecido aquele homem para segurar-te o braço, que o senhor o cubra de bênçãos, estarias agora a levar um cadáver para casa, A ideia foi do senhor, que queria tirar a prova, A prova de quê, Da minha fé, da minha obediência, $E$ que senhor é esse que ordena a um pai que mate o seu próprio filho, É o senhor que temos, o senhor dos nossos antepassados, o senhor que já cá estava quando nascemos, E se esse senhor tivesse um filho, também o mandaria matar, perguntou isaac, $O$ futuro o dirá, Então o senhor é capaz de tudo, do bom, do mau e do pior, Assim é, Se tu tivesses desobedecido à ordem, que sucederia, perguntou isaac, $\mathrm{O}$ costume do senhor é mandar a ruína, ou uma doença, a quem lhe falhou, Então o senhor é rancoroso, Acho que sim, respondeu abraão em voz baixa, como se temesse ser ouvido, ao senhor nada é impossível, Nem um erro ou um crime, perguntou isaac, Os erros e os crimes sobretudo, Pai, não me entendo com esta religião, Hás-de entender-te, meu filho, não terás outro remédio, e agora devo fazer-te um pedido, um humilde pedido, Qual, Que esqueçamos o que se passou, Não sei se serei capaz, meu pai, ainda me vejo deitado em cima da lenha, amarrado, e o teu braço levantado, com a faca a luzir, Não era eu quem estava ali, em meu perfeito juízo nunca o faria, Queres dizer que o senhor enlouquece as pessoas, perguntou isaac, Sim, muitas vezes, quase sempre, respondeu abraão (...) (SARAMAGO, p.81-3, grifos nossos).

Os trechos acima são exemplos da presença do profano como elemento subversivo do sagrado. O narrador associa Deus a características negativas, que acabam por descrever um ser divino com mais "defeitos" do que os humanos que criou. A este respeito, observamos características como a voluntariedade, exemplificada no sacrifício de Isaac, o egoísmo, na desconsideração do sentimento paterno do profeta ao pedir que sacrificasse 
seu filho como prova de obediência, e a crueldade, ao julgar que outro filho poderia substituir o que fora sacrificado.

A partir desta caracterização, ganha espaço o questionamento acerca da obediência cega destinada a este Deus individualista, que não se importa com ninguém além de si e de sua imagem perante os homens. A argumentação se torna ainda mais acentuada no segundo trecho selecionado, quando Isaac, filho de Abrãao, questiona sobre a racionalidade de sacrificar um filho como prova de fé a um Deus que, segundo ele, é inconsequente, rancoroso, enlouquece as pessoas e não tem limites. A personagem de Abraão é ridicularizada, por ter seguido a ordem divina de sacrificar seu único filho como prova desta irracional obediência. O elemento carnavalesco é utilizado pelo narrador como forma de subversão do sagrado, resultando, assim, na apresentação de um mundo às avessas, onde nem tudo é o que parece, mas, quase sempre, seu inverso.

\section{Conclusão}

Em entrevista concedida sobre o livro, o autor português justificou o romance Caim pelo fato de haver muitas pessoas que citavam a Bíblia, mas nunca a haviam lido em suas peculiaridades. Desde a epígrafe, Saramago coloca em evidência a necessidade de repensar a leitura e a interpretação que é feita da Bíblia, uma vez que o mundo contemporâneo não permite a existência do eterno irremediável. Pertencemos a um tempo no qual as verdades vêm com prazo de validade, e, a qualquer momento, podem ser consideradas errôneas. Como, neste contexto, a Bíblia pode ainda ser lida como um elemento atemporal e imutável? Esta é a questão central do romance Caim: a necessidade de racionalização e questionamento do que era, até então, compreendido como perene e inabalável.

A começar pelo narrador, portador de uma voz irônica e crítica sobre o que narra, associado ao processo de autoconsciência ao qual é submetida a personagem Caim e à utilização de recursos como a experimentação de uma verdade, o jogo de oximoros, a sátira menipeia, a palavra inoportuna, o grotesco e a carnavalização, obtêm-se a ressignificação da Bíblia no plano do baixo. Acreditamos que o ponto fundamental da releitura proposta por Saramago em Caim não seja o rebaixamento de valor ou significado da leitura bíblica, mas sim a introdução da racionalidade crítica. De fato, a leitura de Caim é perturbadoramente interessante, uma vez que o romance provoca o leitor ingênuo e faz rir o astuto. 


\section{Referências Bibliográficas}

AUERBACH, Erich. Mimesis: a representação da realidade na literatura ocidental. Vários Tradutores. São Paulo: Perspectiva, 2009.

BAKHTIN, Mikhail. A cultura popular na Idade Média e no Renascimento: o contexto de François Rabelais. Trad.: Yara Frateschi Vieira. São Paulo: Hucitec, 1987.

Questões de Literatura e de Estética. Trad.: Aurora Fornoni Bernardini [et al].

São Paulo: Hucitec, 1990.

Problemas da poética de Dostoiévski. Trad.: Paulo Bezerra. Rio de Janeiro:

Forense Universitária, 2010.

BÍBLIA Sagrada Católica. Disponível em: http://www.bibliacatolica.com.br/

BRAIT, Beth. (org.) Bakbtin: outros conceitos-chave. São Paulo: Contexto, 2010.

MADEIRA, Wagner Martins. Cronotopo: figuração da forma ficcional de Saramago. Bakhtiniana, São Paulo, v.1, n.4, p. 63-75, 2ºm. 2010.

MORSON, Gary Saul; EMERSON, Caryl. Mikhail Bakbtin: criação de uma prosaística. São Paulo: Editora da Universidade de São Paulo, 2008.

SARAMAGO, José. Caim. São Paulo: Companhia das Letras, 2009.

TACCA, Oscar. As vozes do Romance. Trad.: Margarida Coutinho Gouveia. Coimbra: Livraria Almedina, 1983.

Artigo recebido em: 28 de Março de 2012.

Artigo aprovado em: 15 de Novembro de 2012. 